$\mathrm{DE}$

M E D I C I N A

T R O P I C A L

$\mathrm{DE}$

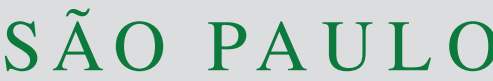

JOURNAL OF THE SÃO PAULO INSTITUTE OF TROPICAL MEDICINE

'Universidade de São Paulo, Faculdade de Filosofia, Ciências e Letras de Ribeirão Preto, Departamento de Biologia, Ribeirão

Preto, São Paulo, Brazil

2Universidade de São Paulo, Faculdade de Medicina de Ribeirão Preto, Programa de Pós-Graduação em Imunologia Básica e Aplicada, Ribeirão Preto, São Paulo, Brazil

${ }^{3}$ Universidade de São Paulo, Faculdade de Medicina de Ribeirão Preto, Departamento de Biologia Celular e Molecular, Ribeirão

Preto, São Paulo, Brazil

Correspondence to: Ademilson PanuntoCastelo

Universidade de São Paulo, Faculdade de Filosofia, Ciências e Letras de Ribeirão Preto, Departamento de Biologia, Av. Bandeirantes, 3900, Monte Alegre, CEP 14040-901, Ribeirão Preto, SP, Brazil

E-mail: apcastelo@usp.br

Received: 2 October 2018

Accepted: 12 November 2018

\section{Quantitation of pulmonary fungal burden in Paracoccidioides brasiliensis-infected mice by real-time PCR}

\author{
Marcelo Vieira Costa ${ }^{1}$, Taise Natali Landgraf ${ }^{\circledR 2}$, Priscila C. Corrêa ${ }^{2}$, \\ Igor Emiliano Lemos Souza ${ }^{2}$, Fabrício Freitas Fernandes ${ }^{3}$, \\ Ademilson Panunto-Castelo 1
}

\section{ABSTRACT}

Although colony-forming unit (CFU) counting is widely used to quantify fungal load in tissue from animal experimentally infected with Paracoccidioides brasiliensis, several technical disadvantages have been described. Here we developed highly accurate quantitative PCR (qPCR) assays to determine the relative $P$. brasiliensis load in lungs from infected mice. SYBR Green- and TaqMan-based assays using primers and probe for the 43-kDa glycoprotein (gp43) gene detected as little as 270 gene copies (about $2 \mathrm{fg}$ of DNA) per reaction. Although qPCR assays cannot distinguish between living and dead yeasts, we found a highly positive linear correlation between $\mathrm{CFU}$ and $\mathrm{qPCR}$.

KEYWORDS: Paracoccidioides brasiliensis. Paracoccidioidomycosis. Quantitative PCR. gp43 gene. Experimental infection. Real-Time PCR.

Paracoccidioidomycosis (PCM) is an endemic disease in Latin America and a serious health issue in Brazil, which has approximately $80 \%$ of cases ${ }^{1}$. This systemic disease has a high disabling potential, mainly by impairment of the pulmonary function of the patients ${ }^{2}$. The etiologic agents of PCM are the fungi species from the Paracoccidioides brasiliensis complex and $P$. lutzi $i^{3}$ whose dimorphism is dependent on temperature since they grow in mycelial form at room temperature and as yeasts at temperatures between $35^{\circ} \mathrm{C}$ and $37^{\circ} \mathrm{C}^{4}$.

The experimental infection of mice with Paracoccidioides, primarily $P$. brasiliensis, has been fundamental to our understanding of PCM including the infection course, pathogenesis and immune response to Paracoccidioides, therapeutic agents, vaccines, among other factors ${ }^{5}$. Due to the absence of PCM treatment with antifungal drugs combining low toxicity and short-term treatment, many researchers, including us, have been looking for molecules that could stimulate the immune system and induce protection against PCM in experimental mouse infections ${ }^{5}$. In most studies of PCM in murine models, there is an estimate of the fungal burden by counting the number of colony-forming units (CFU) from organ homogenates plated on agar medium. Although widely used, several disadvantages of CFU analysis have been described ${ }^{6}$. Regarding the CFU procedure, our main problems are the following: 1) the growth of fungus is relatively slow, ranging from 7 to 14 days to form colonies; 2) the CFU counting is time-consuming; 3 ) the various steps involved in the technique requires a considerable amount of sample and, in a most worrying way, these multiple steps raise the chance of sample contamination, which would further delay the achievement of results.

Currently, advances in molecular biology techniques have shown, in many 
circumstances, that standard procedures are not so appropriate for the quantification of microorganisms ${ }^{7}$. In PCM, some authors have suggested that the amplification of fungal gene sequences by quantitative polymerase chain reaction (qPCR) could be used to PCM diagnosis ${ }^{8,9}$. Thus, in the present study, we aim to standardize a protocol for the quantification of fungal load in the lungs of mice infected with $P$. brasiliensis by using qPCR. The gene of $43-\mathrm{kDa}$ glycoprotein (gp43) from $P$. brasiliensis was chosen as the target of DNA amplification because it contains DNA sequence that code for species-specific peptide epitopes ${ }^{10}$ and therefore is a suitable target for molecular detection approaches. Besides, gp43 is undeniably the most studied among the proteins from $P$. brasiliensis $^{10}$, which in turn is the most used species of the genus Paracoccidioides in experimental infections. To perform qPCR assays with SYBR Green and TaqMan probes, we designed primers to amplify a sequence of 137 nucleotides (nt) within the gp43 gene (GenBank number U26160) - forward, 5'-TCGACACATACCACAACCAAG-3', and reverse 5'- CACTCTTTCACAATCAACGGC-3'. Reactions were performed in duplicate in mixtures that contained $2 \mu \mathrm{L}$ of template DNA (genomic yeast DNA or plasmid pET28a vector containing the gene for gp43 - pET28a-GP43) and $10 \mu \mathrm{M}$ of primers. To the SYBR Green reactions, $12.5 \mu \mathrm{L}$ of SYBR Green qPCR SuperMix-UDG with ROX (Thermo Fisher Scientific Inc., Waltham, USA) and sterile Milli-Q water up to the final volume of $25 \mu \mathrm{L}$ were added to the reaction. TaqMan reactions contained $10 \mu \mathrm{M}$ of the probe (6-FAM-5'-TTAGGACCTTCACCATTGACCAGCAC3'-MGB / NFQ) and $12.5 \mu \mathrm{L}$ of the Advanced Master Mix (Applied Biosystem, Foster City, EUA) instead of SYBR Green. qPCR cycling was performed in a thermal cycler
CFX96 Touch Real-Time PCR Detection System (Bio-Rad, Hercules, EUA), using a hot start of 3 min at $94{ }^{\circ} \mathrm{C}$ followed by 35 cycles of denaturation for $30 \mathrm{~s}$ at $94^{\circ} \mathrm{C}$, annealing for $30 \mathrm{~s}$ at $64^{\circ} \mathrm{C}$, and extension for $30 \mathrm{~s}$ at $72^{\circ} \mathrm{C}$. Amplification analyses were carried out using a CFX Manager Software, version 3.1 (Bio-Rad).

To quantify $P$. brasiliensis from the lung of infected mice by qPCR, we first sought to amplify the gp 43 gene from yeast cells of the virulent $P$. brasiliensis strain $(\mathrm{Pb} 18)$, which was cultured for 7 days at $36{ }^{\circ} \mathrm{C}$ in F12 Nutrient Mixture (HAM) medium with L-glutamine (Life Technologies, Carlsbad, USA). The viability of yeast cells was determined using fluorescein diacetate and ethidium bromide staining ${ }^{11}$. Experiments were performed only with yeast suspensions whose viability was higher than $90 \%$. Yeast genomic DNA was prepared as described ${ }^{12}$ and amplified the sequence of $137 \mathrm{nt}$ within the gp43 gene. Initially, we choose to perform qPCR based on SYBR Green. A strong linear correlation was obtained between quantification cycle values $(\mathrm{Cq})$ and the amount of genomic DNA $(r=0.99, \mathrm{P}<0.005)$ over a range from 200 to 2 ng of DNA (Figure 1A).

Next, we made a standard curve with the plasmid pET28 containing the GP43 gene to determine the copy number of the GP43 gene. By analyzing the pET28a-GP43 size (6,698 bp) and the amount of DNA in serial 10-fold dilution samples ranging from $2 \mathrm{ng}$ to $2 \mathrm{fg}$, the copy number of the GP43 gene was calculated according to the equation described by Whelan et al. ${ }^{13}$.

DNA $($ copy $)=\frac{6.02 \times 10^{23}(\text { copy } / \mathrm{mol}) \times \text { DNA amount }(\mathrm{g})}{\text { DNA length }(\mathrm{bp}) \times 660(\mathrm{~g} / \mathrm{mol} / \mathrm{bp})}$

Quantification cycle values $(\mathrm{Cq})$ from 10 -fold serial
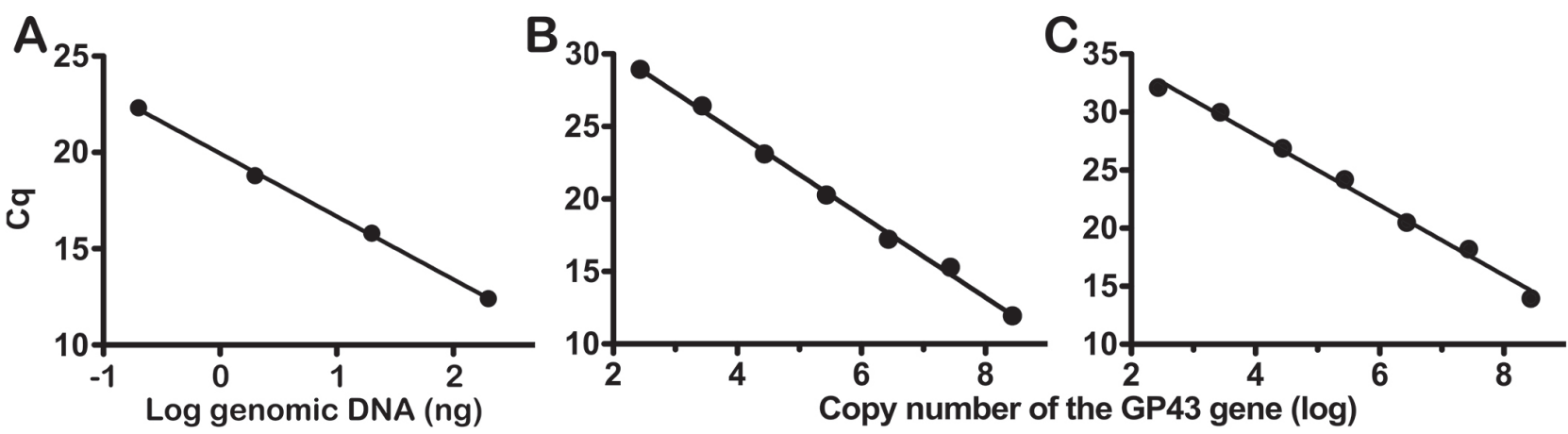

Figure 1 - Standard curves for qPCR - A) Correlation between the amount of genomic DNA from P. brasiliensis (log) and Cq. Four amounts of genomic DNA from P. brasiliensis (ng) were submitted to qPCR using GP43 sequence-specific primers, which amplify $137 \mathrm{nt}$, and the DNA intercalating dye SYBR Green I. Cq (quantification cycle) consists of the number of cycles where there is the intersection of the cut line in the exponential phase of the amplification curve; B and C) Standard curves were constructed by plotting quantification cycle values $(\mathrm{Cq})$ against an estimated DNA copy number to GP43 gene. Serial 10-fold dilutions of the plasmid pET28a-GP43 ranging from $2 \mathrm{ng}$ to $2 \mathrm{fg}\left(2.7 \times 10^{8}\right.$ to $2.7 \times 10^{2}$ copy number) were used as template in a qPCR run to construct the standard curves. The reactions were performed with the primers described above and either the dye SYBR Green I; B) or an allele-specific fluorogenic probe (TaqMan); C). All reactions were preformed in a CFX96 Touch Real-Time PCR Detection System. Error bars represent the standard deviation of duplicate PCR reactions. 
dilutions of the pET28a-GP43 were measured in duplicates by qPCR, as described above. Standard curves were constructed by plotting the $\mathrm{Cq}$ values in each plasmid dilution against the logarithm values of their known initial copy numbers. As expected, we found an inversely proportional relationship between the copy number of the gene and the $\mathrm{Cq}$ when we performed qPCR assays based on SYBR Green (Figure 1B) and TaqMan (Figure 1C) technologies. Strong linear correlation over a range of $2.7 \times 10^{8}$ and $2 \times 10^{2}$ copies was observed for both SYBR Green $(y=-2.826 \log x+35.82, r=0.99, \mathrm{p}<0.005)$ and TaqMan $(y=-3.017 \log x+40.08, r=0.99, \mathrm{p}<0.005)$.

Subsequently, we sought to amplify the sequence of gp43 gene from lungs of $P$. brasiliensis-infected mice. Male BALB/c mice, 6 to 8 weeks old were purchased from the Central Animal House of the Ribeirao Preto Campus of University de Sao Paulo (USP) and maintained in the Animal Facilities of the Department of Biology, Faculty of Philosophy, Sciences and Letters of Ribeirao Preto, USP. All procedures were in accordance with the Guide for the Care and Use of Laboratory Animals of the National Research Council and was approved by the Ethics Committee on Animal Use of the Ribeirao Preto Medical School, USP, protocol No 105/2007.

Mice were anesthetized by peritoneal injection of $100 \mu \mathrm{L}$ of a solution containing ketamine $(85 \mathrm{mg} / \mathrm{kg})$ and xylazine $(10 \mathrm{mg} / \mathrm{kg})$ (both from Union Chemical, Embu, Brazil), intravenously inoculated with $100 \mu \mathrm{L}$ of fungal suspension of virulent $P$. brasiliensis $\left(1 \times 10^{7}\right.$ viable yeasts/ $\mathrm{mL}$ ) and daily monitored for signs of distress or illness and mortality. None of them became seriously ill or died prior to the experimental endpoint. The treatment protocol was carried out as previously described ${ }^{14}$. Briefly, groups of five infected mice were subcutaneously injected on day 21 after infection with $100 \mu \mathrm{L}$ of monophosphoryl lipid A from Salmonella minnesota (MPLA, Invivogen, San Diego, USA) and phosphate buffered saline (PBS). The control group was treated with PBS as the infection control. After 30 days of treatment ( 50 after infection), the animals in each experimental group were euthanized and the lungs were aseptically removed and weighed.

Because $P$. brasiliensis infection in mice preferentially occurs in the left lung when intravenous inoculation is used ${ }^{15}$, we homogenized that lung in $1 \mathrm{~mL}$ of sterile PBS using T25 Basic Ultra-Turrax (IKA Works, Inc., Wilmington, USA). Aliquots of $100 \mu \mathrm{L}$ of 1:10 diluted lung suspensions were plated in duplicate on Petri dishes containing BHI agar (Oxoid Limited, Basingstoke, UK) supplemented with 4\% (v/v) FBS (Hyclone Laboratories, Logan, USA). Plates were incubated at $36{ }^{\circ} \mathrm{C}$ for 7 days. Subsequently, fungal colonies were counted and results were expressed as number of CFU per gram of tissue (CFU/g).

Initially, we sought to amplify the sequence of $137 \mathrm{nt}$ within the gp43 gene directly with 200 ng of DNA from homogenates of lungs of three $P$. brasiliensis-infected mice. Under these conditions, there were amplification curves, but positive samples were at the late PCR cycles $(>31$ $\mathrm{Cq}$ ), which did not correlate with high fungal load (about $10^{6}$ yeast/g) found in the lungs (data not shown). These results suggested that the late DNA amplification from the homogenates might be due to a small amount of fungal DNA present in lung homogenates when compared with the amount of mouse DNA. To overcome this problem, we concentrated the yeasts from the remaining lung homogenates using a three-step protocol, previously described to isolate Blastomyces dermatitidis from murine lung ${ }^{16}$. Firstly, we diluted the homogenate 1:25 in ultrapure water (Direct-Q 3 UV, Merck Millipore, Hayward, USA) and the solution was maintained for 10 minutes for complete lysis of lung cells. Afterwards, lung homogenates were filtered through a 70- $\mu \mathrm{m}$ nylon mesh cell strainer (Thermo Fisher Scientific Inc.) to remove the fibers and extracellular matrix. The filtered and diluted homogenates were centrifuged at $10,000 \times \mathrm{g}$, for 5 $\mathrm{min}$, at $4{ }^{\circ} \mathrm{C}$ and the pellets were re-suspended in $20 \mathrm{~mL}$ of ice-cold ultrapure water, and centrifuged as described above. The pellets were then washed three times. Remarkably, the procedure described by Marty et al. ${ }^{16}$ was reproducible and reliable to obtain clean concentrates of $P$. brasiliensis yeast cells and provided around $90 \%$ of yeast cells recovery with few contaminants (data not shown).

To determinate whether there was a correlation between CFU and DNA copy number from the GP43 gene, data of both parameters were plotted and analyzed (Figure 2). In a pilot experiment with lung samples from five mice (Figure 2A and 2B), we showed that the protocol could be suitable for both qPCR methods, SYBR Green and Taqman. In the experiments with samples from 10 mice, five treated with PBS (control) and five treated with MPLA, there was a good correlation between the copy number of the gp 43 gene and the fungal burden (CFU/g lung) for both SYBR Green$(r=-0.97, \mathrm{p}<0.0001)$ (Figure 2C) and Taqman-based assays $(r=-0.94, \mathrm{p}<0.0001)$ (Figure 2D). Therefore, the protocol here developed proved to be efficient and enabled the evaluation of treatment performed in $P$. brasiliensis-infected mice. In this trial, it was clear that MPLA significantly decreased the fungal load, as previously described ${ }^{14}$. Taking into consideration that these small variations were identified only among the analyzed methods, but maintained the same results found between PBS and MPLA groups, the quantification method of pulmonary fungal burden by real-time PCR is a potential tool for investigations in 

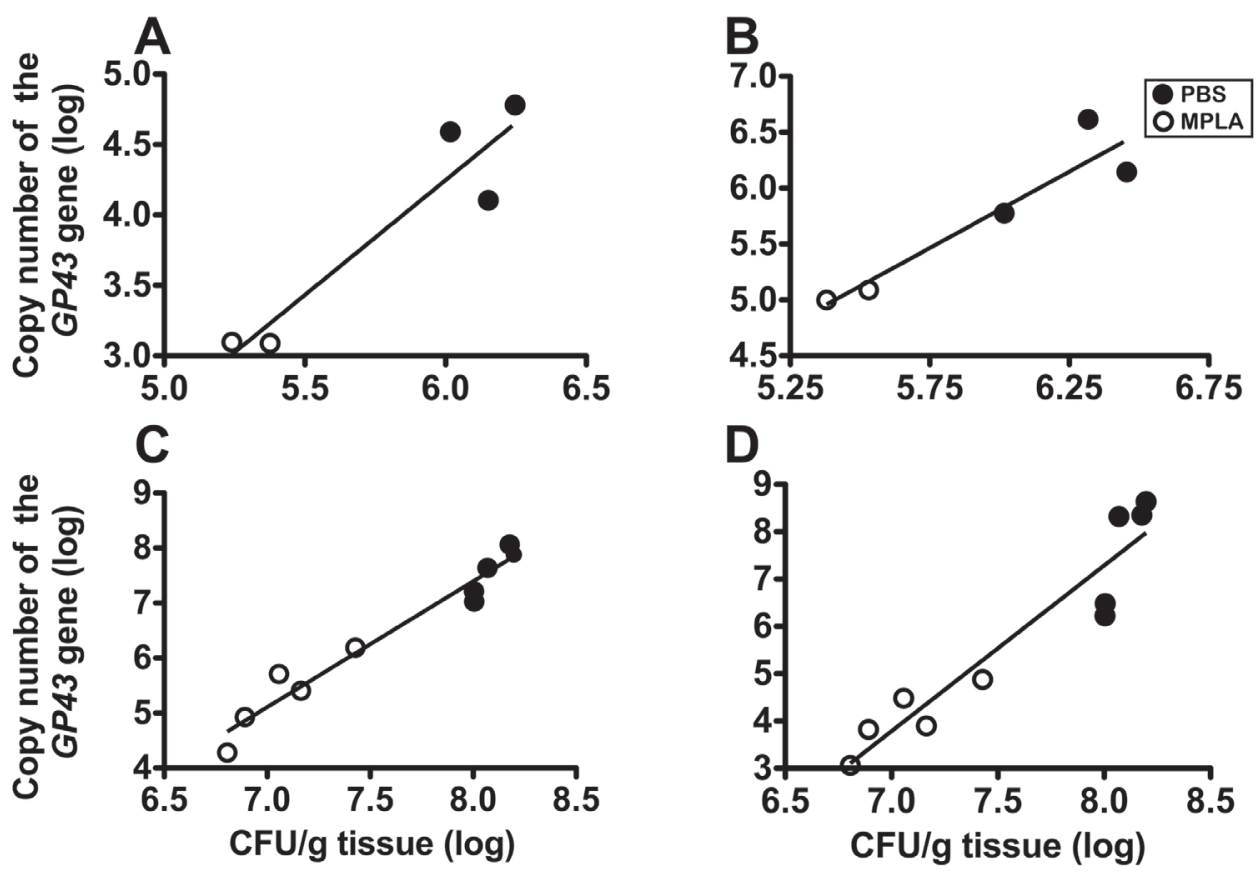

Figure 2 - The relationship between CFU per gram of lung and copy number of the GP43 gene obtained from the lung homogenates of $P$. brasiliensis-infected mice. BALB/c mice infected with $P$. brasiliensis were injected with emulsion PBS/MPLA (open circles) or PBS only (closed circles) on day 21 after infection. On day 30 after treatment, i.e., 50 days after infection, lung homogenates were used both to determine the fungal load by CFU assay and the copy number of the GP43 gene. DNA samples to quantify the GP43 gene were extracted from $P$. brasiliensis suspensions, which were obtained from lung homogenates free of host cells and cellular debris. Copy number was determined from a Cq standard curve, as described in Figure 1, with SYBR green (A and C) or TaqMan (B and D). A and B indicate a pre-test with five mouse and C and D experiments with 10 mice. The results represent the mean \pm standard deviation values. Similar results to those of the $C$ and $D$ graphs were obtained in two independent experiments.

experimental PCM in mice. Corroborating these results, several others studies have already used the real-time PCR method to evaluate the fungal load ${ }^{17,18}$, regardless of the variations between the possible methods to be employed.

Briefly, we report here that there is a strong correlation between the data obtained from qPCR and the CFU count, making evident that molecular detection is a robust alternative for use in experimental models. This tool can be of great value, since it makes the quantification faster, reducing the chances of contamination and exhibiting considerable sensitivity.

\section{FUNDING}

This work was supported by Fundação de Amparo à Pesquisa do Estado de São Paulo (FAPESP) under grants No 2013/12278-3 and 2017/01390-8.

\section{CONFLICT OF INTERESTS}

The authors report no conflicts of interest. The authors alone are responsible for the content and the writing of the manuscript.

\section{ACKNOWLEDGMENTS}

MVC and PCC received an institutional scholarship for undergraduate students (PIBIC) from National Council for Scientific and Technological Development (CNPq).

\section{REFERENCES}

1. Sifuentes-Osornio J, Corzo-León DE, Ponce-de-León LA. Epidemiology of invasive fungal infections in Latin America. Curr Fungal Infect Rep. 2012;6:23-34.

2. Shikanai-Yasuda MA, Telles Filho FQ, Mendes RP, Colombo AL, Moretti ML. Consenso em paracoccidioidomicose. Rev Soc Bras Med Trop. 2006;39:297-310.

3. Teixeira MM, Theodoro RC, de Carvalho MJ, Fernandes L, Paes HC, Hahn RC, et al. Phylogenetic analysis reveals a high level of speciation in the Paracoccidioides genus. Mol Phylogenet Evol. 2009;52:273-83.

4. Bagagli E, Bosco SM, Theodoro RC, Franco M. Phylogenetic and evolutionary aspects of Paracoccidioides brasiliensis reveal a long coexistence with animal hosts that explain several biological features of the pathogen. Infect Genet Evol. 2006;6:344-51. 
5. Goldani LZ, Wirth F. Animal models and antifungal agents in paracoccidioidomycosis: an overview. Mycopathologia. 2017;182:633-43.

6. Sutton S. The limitations of CFU: compliance to CGMP requires good science. J GXP Compliance. 2012;16:74-80.

7. Filion M, editor Quantitative real-time PCR in applied microbiology. Norfolk: Caister; 2012.

8. Buitrago MJ, Merino P, Puente S, Gomez-Lopez A, Arribi A, Zancope-Oliveira RM, et al. Utility of real-time PCR for the detection of Paracoccidioides brasiliensis DNA in the diagnosis of imported paracoccidioidomycosis. Med Mycol. 2009;47:879-82.

9. Gomes GM, Cisalpino PS, Taborda CP, de Camargo ZP. PCR for diagnosis of paracoccidioidomycosis. J Clin Microbiol. 2000;38:3478-80.

10. Puccia R, McEwen JG, Cisalpino PS. Diversity in Paracoccidioides brasiliensis. The PbGP43 gene as a genetic marker. Mycopathologia. 2008;165:275-87.

11. Calich VL, Purchio A, Paula CR. A new fluorescent viability test for fungi cells. Mycopathologia. 1979;66:175-7.

12. Sambrook J, Russell DW. Growth of S. cerevisiae and preparation of DNA. CSH Protoc. 2006;2006:3298.
13. Whelan JA, Russell NB, Whelan MA. A method for the absolute quantification of cDNA using real-time PCR. J Immunol Methods. 2003;278:261-9.

14. Landgraf TN, Fernandes FF, Peron G, Panunto-Castelo A. Therapeutic effect of monophosphoryl lipid A administration on Paracoccidioides brasiliensis-infected mice. Med Mycol. 2017;55:344-8.

15. Tristão FS, Rocha FA, Dias FC, Rossi MA, Silva, JS. The left lung is preferentially targeted during experimental paracoccidioidomycosis in C57BL/6 mice. Braz J Med Biol Res. 2013;46:839-43.

16. Marty AJ, Wüthrich M, Carmen JC, Sullivan TD, Klein BS, Cuomo CA, et al. Isolation of Blastomyces dermatitidis yeast from lung tissue during murine infection for in vivo transcriptional profiling. Fungal Genet Biol. 2013;56:1-8.

17. Khot PD, Fredricks DN. PCR-based diagnosis of human fungal infections. Expert Rev Anti Infect Ther. 2009;7:1201-21.

18. Kourkoumpetis TK, Fuchs BB, Coleman JJ, Desalermos A, Mylonakis E. Polymerase chain reaction-based assays for the diagnosis of invasive fungal infections. Clin Infect Dis. 2012;54:1322-31 